\title{
Stenotic Lesions and the Bifurcation Angle of Coronary Arteries in the Young
}

\author{
Uichi Ikeda, M.D., Masatoshi Kuroki, M.D., \\ Takashi EjIri, M.D., Saichi Hosoda, M.D.,* \\ and Toshio Yaginuma, M.D.
}

\begin{abstract}
SUMMARY
To determine the genesis of the high incidence of stenotic lesions of the left anterior descending artery (LAD) in the young, we have investigated the anatomical characteristics of coronary arteries in the following 3 groups; young ( $\leq 40 \mathrm{yr}$ ) myocardial infarction (MI) patients with LAD lesions, young ( $\leq 40 \mathrm{yr}$ ) patients without coronary stenosis and aged ( $\geq 60$ yr) MI patients. The angle between the left main coronary artery (LMT) and the LAD in the young MI patient group $\left(146.7 \pm 7.4^{\circ}\right)$ was significantly wider than those of the young normal $\left(126.0 \pm 13.4^{\circ}\right)$ or the agcd MI paticnt groups $\left(127.1 \pm 18.6^{\circ}\right)(\mathrm{p}<0.01, \mathrm{p}<0.02$, respectively). The angle between the LMT and the left circumflex artery (LCX), and the angle between the LAD and the LCX were not significantly different among the 3 groups. The LMT length in the young MI patient group was $18.3 \pm 4.7 \mathrm{~mm}$, which was not significantly longer than those of the young normal $(12.7 \pm 6.9 \mathrm{~mm})$ or the aged patient groups $(14.8 \pm 6.0$ $\mathrm{mm}$ ). The internal diameter ratio of the LAD and LCX was also not significantly different among the 3 groups. These results suggest that the angle between the LMT and LAD was significantly wider in young MI patients, and should be regarded as an inherited characteristic influencing the development of coronary atherosclerosis of the LAD, particularly in young MI patients.
\end{abstract}

\section{Key Words :}

Myocardial infarction Angiography Left anterior descending artery Left main coronary artery

$\mathrm{F}$ ROM a large variety of suggested etiological factors in the pathogenesis of athcrosclerosis, mcchanical stresses and hemodynamic changes resulting from anatomical variations in the structure of coronary arteries have been considered as a sine qua non. ${ }^{1,2)}$ Other known factors predisposing to the development of atherosclerosis might be only secondary or merely modify its

From the Department of Cardiology, Jichi Medical School, Tochigi and *The Heart Institute of Japan, Tokyo Women's Medical College, Tokyo, Japan.

Address for correspondence: Uichi Ikeda, M.D., Department of Cardiology, Jichi Medical School, Minamikawachi, Tochigi 329-04, Japan.

Received for publication August 16, 1990.

Accepted February 18, 1991. 
course. The presence of hyperlipidemia, for example, would enhance atherosclerotic lesions situated at areas where local mechanical stresses are likely to be greatest.

It is well documented that a single-vessel stenotic lesion is frequently seen in young myocardial infarction (MI) patients and the most commonly affected vessel is the left anterior descending artery (LAD) at sites \#6 and \# 7 of the American Heart Association (AHA) classification, followed by right and left circumflex coronary arteries (LCX). On the contrary, the frequency of multivessel lesions increases with age. To determine the genesis of this high incidence of LAD lesions in young MI patients, we have investigated those anatomical characteristics that might have a relation to the development of LAD lesions.

\section{Methods}

The male patients who underwent cinecoronary angiography at Jichi Medical School Hospital were divided into 3 groups. The first group in cluded 21 MI paticnts under $40 \mathrm{yr}$ (mean=34.3) with significant stenotic lesions ( $\geq 75 \%$ stenosis) of any vessel (young patient group). The second group included 8 patients under $40 \mathrm{yr}$ (mean=30.6) complaining of chest pain without angiographic evidence of coronary atherosclerosis (young normal group). The third group included $25 \mathrm{MI}$ patients over $60 \mathrm{yr}(\mathrm{mean}=64.7)$ with significant stenotic lesions of any vessel (aged patient group).

Assessments were made of consecutive coronary angiograms carried out by the Judkins or Sones technique. Measurements were performed in both the right anterior oblique $\left(\mathrm{RAO} 30^{\circ}\right.$ ) and left anterior oblique (LAO $60^{\circ}$ ) projections in the diastolic phase. To determine three aspects [(i) length of the left main coronary artery (LMT), (ii) bifurcation angles among LMT, LAD and LCX, (iii) caliber ratio of LAD and LCX], three-dimensional structures were obtained by measuring the following four points from bidirectional planes (Fig. 1); (A) the orifice of the LMT, (B) the bifurcation-point of the LAD and LCX, (C) the branch-point of the first septal branch, (D) the branch-point of the obtuse marginal artery. For example, the spatial length of the LMT (A-B) was determined from its origin (point A; visualized by spillback of contrast medium into the aorta during selective injection) to the point of its bifurcation into LAD and LCX (point B) from two projections perpendicular to one another, as was done by previous investigators. ${ }^{3)}$ The spatial length was estimated by using Pythagoras' theorem; $V=\sqrt{\mathrm{R}^{2}+\mathrm{L}^{2}}$, where $\mathrm{V}=$ spatial length, and $\mathrm{R}$ and $\mathrm{L}=$ length in right and left anterior oblique projections. The spatial lengths of A-C, A-D, B-C, B-D, and D-C were 


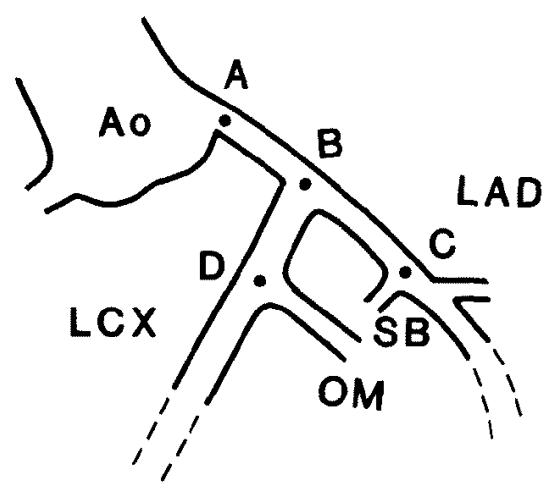

Fig, 1. To determine three aspects [length of left main coronary artery (LMT), bifurcation angles among LMT, left anterior descending artery (LAD) and left circumflex artery (LCX), caliber ratio of LAD and LCX], threedimensional structures were obtained by measuring the following four points from bidirectional planes, right anterior oblique (RAO $30^{\circ}$ ) and left anterior oblique (LAO $60^{\circ}$ ) projections in the diastolic phase; (A) the orifice of LMT, (B) the bifurcation-point of LAD and LCX, (C) the branch-point of the first septal branch (SB), (D) the branch-point of the obtuse marginal artery (OM).

cstimated in the same way, and bifurcation angles among LMT, LAD and LCX were determined from those spatial lengths. Correction for magnification was made by calculating the ratio of the projected diameter of the Judkins or Sones catheter to its actual diameter. Results were expressed as the mean $\pm \mathrm{SE}$ and statistical analysis was performed by Student's t-test; $\mathrm{p}$ values less than $5 \%$ were considered to be significant.

\section{Results}

Table I shows the distribution of stenotic lesions in the 3 groups. In young MI patients $(n=21)$, the LAD one-vessel lesion comprised $43 \%$, while in aged MI patients $(n=25)$ its percentage was only $10 \%$ and significantly lower $(\mathrm{p}<0.05)$ than that in young MI patients. Among coronary risk factors such as hyperlipidemia, smoking, diabetes, hypertension and hyperuricemia, the percentage of hyperlipidemia and smoking was significantly higher in young MI patients compared with aged MI patients (data not shown).

Next, to determine the genesis of the high incidence of LAD stenotic lesions in young MI patients, we compared the bifurcation angles of coronary arteries among the 3 groups; 9 young MI patients with LAD lesions, 8 young normal patients and 9 aged MI patients. Cases where it was impossible to make precise assessments of coronary arteries, or with left ventricular an- 
Table I. Distribution of Stenotic Lesions in Young MI Patients $(\mathrm{MI} \leq 40)$ and Aged MI Patients $(\mathrm{MI} \geq 60)$

\begin{tabular}{|c|c|c|c|c|}
\hline & & $\begin{array}{c}M ! \\
(n=21)\end{array}$ & $\begin{array}{c}M I \geq 60 \\
(n=20)\end{array}$ & \\
\hline \multicolumn{5}{|l|}{ One vessel } \\
\hline & LAD & $9(43 \%)$ & $2(10 \%)$ & $p<0.05$ \\
\hline & $\begin{array}{l}\text { LCX } \\
\text { RCA }\end{array}$ & $\begin{array}{ll}1 & (5 \%) \\
6 & (28 \%)\end{array}$ & $\begin{array}{ll}1 & (5 \%) \\
4 & (20 \%)\end{array}$ & $\begin{array}{l}\text { ns } \\
\text { ns }\end{array}$ \\
\hline Two vessel & & $4(19 \%)$ & $11(55 \%)$ & $p<0.05$ \\
\hline Three vessel & & $1 \quad(5 \%)$ & $2(10 \%)$ & ns \\
\hline
\end{tabular}

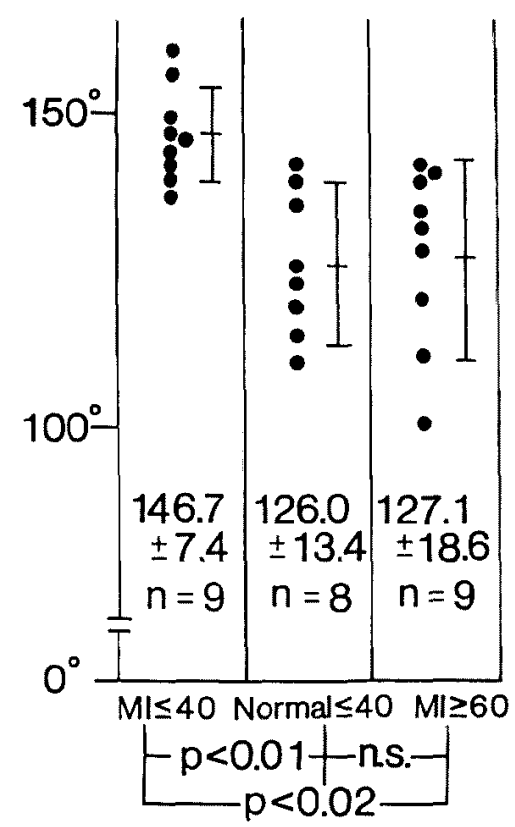

Fig. 2. The bifurcation angle between LMT and LAD in the 3 groups. The angle in the young $\mathrm{MI}$ patient group $(\mathrm{MI} \leq 40)$ was significantly wider than that of the young normal (Normal $\leq 40)$ or aged MI patient $(M I \geq 60)$ groups. The data are mean $\pm \mathrm{SE}$.

eurysm on left ventriculography were excluded from the assessments. As shown in Fig. 2, the angle between the LMT and LAD in the young MI patient group $\left(146.7 \pm 7.4^{\circ}\right)$ was significantly wider than those of the young normal $\left(126.0 \pm 13.4^{\circ}\right)$ and the aged MI patient groups $\left(127.1 \pm 18.6^{\circ}\right)(\mathrm{p}<$ $0.01, \mathrm{p}<0.02$, respectively). However, the angle between the LMT and LCX, and the angle between the LAD and LCX were not significantly different among the 3 groups (Table II). The LMT length in the young 
Table II. The Bifurcation Angles of Coronary Arteries, the LMT Length and the Caliber Ratio of LAD and LCX in Young MI Patients (MI $\leq 40$ ), Young Normal Patients (Normal $\leq 40)$ and Aged MI Patients $(\mathrm{MI} \geq 60$ )

\begin{tabular}{|c|c|c|c|c|}
\hline & $\begin{array}{c}M I \leq 40 \\
(n=8)\end{array}$ & $\begin{array}{c}\text { Normal } \leq 40 \\
(n=9)\end{array}$ & $\begin{array}{c}M I \geq 60 \\
(n=8)\end{array}$ & \\
\hline $\begin{array}{l}\text { Angle between } \\
\text { LMT and LCX }\end{array}$ & $109.2 \pm 22.9^{\circ}$ & $100.4 \pm 30.8^{\circ} 1$ & $114.6 \pm 13.7^{\circ}$ & ns \\
\hline $\begin{array}{l}\text { Angle between } \\
\mathrm{LAD} \text { and LCX }\end{array}$ & $84.3 \pm 19.5^{\circ}$ & $81.4 \pm 19.3^{\circ}$ & $91.6 \pm 21.2^{\circ}$ & ns \\
\hline Length of LMT & $18.3 \pm 4.7 \mathrm{~mm}$ & $\mathrm{~m} 12.7 \pm 6.9 \mathrm{~mm}$ & $14.8 \pm 6.0 \mathrm{~mm}$ & ns \\
\hline $\begin{array}{l}\text { Caliber ratio of } \\
L A D \text { and } L C X\end{array}$ & $0.95 \pm 0.30$ & $0.97 \pm 0.17$ & $1.02 \pm 0.14$ & ns \\
\hline
\end{tabular}

The data are mean \pm SE

MI patient group was $18.3 \pm 4.7 \mathrm{~mm}$, which was not significantly longer than those of the young normal $(12.7 \pm 6.9 \mathrm{~mm})$ or the aged MI patient groups $(14.8 \pm 6.0 \mathrm{~mm})(\mathrm{p}>0.05)$. The internal diameter ratio of the $L A D$ and LCX (LAD/LCX) was also not significantly different among the 3 groups.

\section{Discussion}

The present study demonstrates a high incidence of LAD lesions in young MI patients, in agreement with previous reports. ${ }^{4)}$ Although the mechanisms that produce this tendency to LAD distribution of atherosclerosis in the young are not known, hemodynamic factors may be important, especially changes in arterial wall shear stress which is proportional to flow rate.

The importance of the bifurcation angle in altering hemodynamics and hence atherogenesis has been investigated experimentally., Increased flow and variables related to changes of flow such as shear stress have been considered as atherogenic hydraulic factors acting mainly on sites of bifurcation, branching, bending, and narrowing. ${ }^{6)}$ The wider angle $\left(+20^{\circ}\right)$ between LMT and LAD in young MI patients compared with young normal or aged MI patients (Fig. 2) is speculated to accelerate the peak flow rate at the LAD and thus facilitate the atherogenic effect of mechanical forces in young MI patients. The abundance of elastin, glycosaminoglycans or smooth muscle fibers at the proximal LAD might also contribute to the development of atherogenesis at this site."

Saltissi et $\mathrm{al}^{31}$ have previously compared the bifurcation angle between the LAD and LCX in patients with and without proximal stenotic lesions. The mean bifurcation angle was not significantly different between the groups 
with proximal lesiors $\left(81^{\circ}\right)$ and without disease $\left(75^{\circ}\right)(\mathrm{p}>0.05)$. In our study, the angle between the LAD and LCX was not significantly different between young patients with LAD lesions $\left(84^{\circ}\right)$ and without disease $\left(81^{\circ}\right.$ ) (Table II). The angle between the LMT and LCX, and the internal diameter ratio of the LAD and LCX were also similar between the 2 groups.

Other than the bifurcation angle, the LMT length has been speculated to be involved in the pathogenesis of LAD lesions, and has been estimated at angiography or necropsy. ${ }^{3,8)-10)}$ A previous angiographic study found a shorter LMT in patients with LAD atheromatous lesions. ${ }^{3)}$ However, the present study showed that the LMT length was not significantly shorter in young MI patients with LAD lesions, as reported by Penther et $\mathrm{al}^{9 \text { ) }}$ or Ohkawa et al. ${ }^{101}$

Anatomical structure and distribution of the coronary tree are possibly determined by heredity and development, as are other morphological characteristics. Due to the large variations in the anatomic structure of human coronary arteries, it is difficult to generalize the above findings to all young MI patients. Although further studies are necessary to confirm our hypothesis, the present study suggests that the angle between the LMT and LAD should be regarded as an inherited characteristic influencing the development of coronary atherosclerosis at the LAD, particularly in the young.

\section{ACKNOWLEDGMents}

We thank H. Shimada and S. Tanaka for assistance in preparing this manuscript.

\section{REFERENGES}

1. Gazetopoulos N, Ioannidis PJ, Marselos A, Kelekis D, Lolas C, Avgoustakis D, Tountas C: Length of main left coronary artery in relation to atherosclerosis of its branches. Br Heart $J$ 38: 180,1976

2. Asakura $T$, Karino $T$ : Flow patterns and spatial distribution of atherosclerotic lesions in human coronary arteries. Circ Res 66: 1045, 1990

3. Saltissi $\mathrm{S}$, Webb-peploe MM, Coltart $\mathrm{DJ}$ : Effect of variation in coronary artery anatomy on distribution of stenosis lesions. Br Heart J 42: 186, 1979

4. Fox B, James K, Morgan B, Seed A: Distribution of fatty and fibrous plaques in young human coronary arteries. Atherosclerosis 41: 337, 1982

5. Brech R, Bellhouse BJ: Flow in branching vessels. Cardiovasc Res 7: 593, 1973

6. Texon M: A hemodynamic concept of atherosclerosis, with particular reference to coronary occlusion. Arch Intern Med 99: 418, 1957

7. Robert L, Birembaut P: Extracellular matrix of the arterial vessel wall. in Diseases of the Arterial Wall, ed by Camilleri J, Springer-Verlag, Berlin, p 55, 1989

8. Kronzon I, Deutsch P, Glassman E: Length of the left main coronary artery. Its relation to the pattern of coronary artery distribution. Am J Cardiol 34: 787, 1974

9. Penther PH, Boschat J, Morin JF, Blanc JJ, Granatelli D: The length of the left main coro- 
nary artery. Am Heart J 94: 705, 1977

10. Ohkawa S, Imai T, Kuboki K, Chida K, Watanabe C, Shimada H, Ohtsubo K, Sugiura M: Stenotic lesions and length of the left main coronary artery in the aged. Jpn Heart $\mathrm{J} 30: 779$, 1989 